\title{
GRANTA “DEFININDO OS CONTORNOS DO CENÁRIO LITERÁRIO”
}

\author{
Lilia Baranski Feres \\ Valéria Silveira Brisolara \\ UniRitter
}

RESUMO: No ano de 2012, na Inglaterra, veio a público o volume 121 do periódico literário inglês Granta: The best of young Brazilian novelists. Essa publicação se deu a partir da tradução de Os melhores jovens escritores brasileiros, obra que havia sido publicada meses antes no Brasil como resultado do Projeto Granta em Português. Os fítulos dessa coleção, lançados a cada dez anos, operam como meio de introduzir ao público leitor autores contemporâneos que apresentam uma promissora carreira literária. A fim de investigar o papel potencialmente definidor de periódicos literários desse tipo, o presente artigo analisa material integrante dos dois volumes, tanto texto quanto paratexto, com fundamentação teórica de autores como Even-Zohar, que aborda as restrições e coerções exercidas na transferência de bens culturais dentro do sistema literário; Bourdieu, que trata do poder inerente ao uso da linguagem; e Foucault que discute as características e o papel desempenhado pela entidade autor.

PALAVRAS-CHAVE: Revista literária Granta. Cultura. Literatura.

\section{GRANTA \\ "DEFINING THE CONTOURS OF THE LITERARY LANDSCAPE"}

ABSTRACT: In 2012, in England, the 121th volume issue of Granta, The best of young Brazilian novelists, was published. This publication was based on the translation of Os melhores jovens escritores brasileiros, which had been previously published in Brazil as a result of the Granta em Português project. The titles of this collection, released every ten years, operate as a means of introducing to readers the contemporary writers of each generation who hold a promising literary career. In order to investigate the potential defining role of literary journals such as Granta, this article analyzes the two volumes, both text and paratext, based on theories from authors like Even-Zohar that deals with restrictions and coercions imposed in the transfer of cultural goods within the literary system; Bourdieu, that writes about the inherent power of language use; and Foucault, who deals with the features and role played by the author entity.

KEYWORDS: Granta literary magazine. Culture. Literature.

Lilia Baranski Feres é mestre em Letras pelo Centro Universitário Ritter dos Reis.

Valéria Silveira Brisolara é tradutora juramentada (JUCERGS-RS) e membro da ASTRAUUR-RS, professora titular no Centro Universitário Ritter dos Reis. 


\title{
GRANTA \\ “DEFININDO OS CONTORNOS DO CENÁRIO LITERÁRIO”
}

\author{
Lilia Baranski Feres \\ Valéria Silveira Brisolara
}

\section{CONSIDERAÇÕES INICIAS}

A Granta é uma tradicional revista literária em língua inglesa. Em 2012, foi publicado, na Inglaterra, o título The best of young Brazilian novelists, o volume 121 da longa história da revista. Tratava-se de uma edição um pouco posterior ao volume 9 da Granta em português, publicada no Brasil sob o mesmo título Os melhores jovens escritores brasileiros. A obra, como seu título indica, se propõe a apresentar os nomes que considera os mais promissores dentre os autores contemporâneos brasileiros da última década.

A publicação desses dois títulos chamou nossa atenção e despertou o interesse em investigar o papel potencialmente definidor de periódicos literários desse tipo. Assim, este artigo analisa material integrante dos dois volumes, considerando tanto texto quanto paratexto. ${ }^{1} \mathrm{~A}$ fundamentação teórica baseia-se na contribuição de autores como Even-Zohar², que aborda o que chama de sistema literário, bem como as restrições e coerções exercidas na transferência de bens culturais dentro desse sistema literário; Bourdieu ${ }^{3}$, que trata do poder inerente ao uso da linguagem em diferentes contextos sociais; e Foucault ${ }^{4}$, que discute as características e o papel desempenhado pela entidade autor.

A fim de atingir o objetivo proposto, o artigo primeiramente apresenta a revista literária Granta, para depois analisar os dois volumes que compõem o objeto de investigação no âmbito deste artigo e refletir sobre a relevância de tais iniciativas no nosso cenário editorial e literário. Parte dos dados aqui apresentados integra uma pesquisa mais complexa e abrangente.

${ }^{1}$ GENETTE, Gerárd. Paratexts: thresholds of interpretation. Trad. Jane E. Lewin. Cambridge: Cambridge University Press, 2001.

2 EVEN-ZOHAR, Itamar. Polysystem studies. Poetics Today, Durham, v. 11, n. 1, 1990.

3 BOURDIEU, Pierre. A economia das trocas linguísticas. In: ORTIZ, Renato (Org.). Pierre Bourdieu: sociologia. São Paulo: Ática. Coleção grandes cientistas sociais, v. 39, 1983, p. 156183.

4 FOUCAULT, Michel. O que é um autor? Trad. Antônio Fernando Cascais e Eduardo Cordeiro. Belo Horizonte: FALE/UFMG, 2011, p. 51-82. 


\section{A REVISTA GRANTA}

De acordo com informações retiradas de seu site oficial ${ }^{5}$, a revista Granta foi fundada há muito tempo, em 1889. Sua idealização surgiu com alunos da Universidade de Cambridge e desde sua concepção foi chamada de Granta, como forma de homenagear o rio que cruza a cidade. Inicialmente, a Granta exercia a função de periódico para fins de divulgação de políticas estudantis, chistes e projetos literários. Sua versão inaugural publicou textos de escritores como A. A. Milne, autor das narrativas aventureiras do mundialmente conhecido ursinho Puff; Michael Frayn, dramaturgo inglês que assina Golpe de mestre, Espiões, entre outros romances e peças de teatro, e vencedor de vários prêmios literários; Stevie Smith, Ted Hughes, autor de numerosos romances e livros infantis, dentre eles $O$ homem de ferro, $O$ caçador de sonhos e $O$ que é verdade? (obras que foram publicadas em português); e Sylvia Plath, que assina A redoma de vidro, entre outros títulos de prosa e poesia.

No ano de 1979, a Granta sofreu uma reconfiguração. Perdeu seu caráter de publicação estudantil e ganhou o status de revista literária trimestral marcada pelo estilo e formatação que conserva até os dias de hoje. Uma década mais tarde, os livros Granta foram introduzidos, adquirindo rapidamente seu status de grande prestígio e independência como editora literária no Reino Unido. Suas edições temáticas apresentam desde ganhadores de prêmio Nobel até escritores novatos, desde tradutores internacionais até material de jornalismo investigativo. São conteúdos que, de acordo com o site, "turns the attention of the world's best writers on to one aspect of the way we live now." ${ }^{6}$

Os títulos do tipo "Os melhores jovens escritores [...]" são publicados a cada dez anos e visam apresentar os mais promissores nomes de cada geração. Edições anteriores introduziram "os melhores jovens escritores" da Inglaterra, dos Estados Unidos, do Brasil e da Espanha. A Granta defende que suas edições vêm "defining the contours of the literary landscape since 1983."7 Esta frase é de fundamental importância, pois vai ao encontro de outra afirmação da revista

\footnotetext{
${ }^{5}$ Granta: the magazine of new writing. Desenvolvido por Salu, a creative studio.

${ }^{6}$ Chamam atenção dos melhores escritores do mundo para um aspecto da forma como vivemos agora. Traduções em rodapé sob responsabilidade das autoras.

7 Definindo os contornos do cenário literário desde 1983.
} 
que reitera sua crença institucional de "não ter uma agenda política ou literária", ao passo que confere a si mesma um alto prestígio e poder de decisão.

A publicação Os melhores jovens escritores britânicos, de 1983, listava vinte nomes, com idade inferior a 40 anos, com um futuro promissor na carreira literária do Reino Unido. O rol parece ter sido uma certeira previsão - ou uma eficaz ferramenta de influência -, já que entre os nomes constavam figuras altamente prestigiadas no campo literário britânico atual. Entre eles, Martin Amis, autor de Grana (na lista do jornal The Guardian ${ }^{8}$ dos 100 melhores livros), A casa dos encontros, Trem noturno, entre outros; Julian Barnes, vencedor do Man Booker Prize 2011 com sua obra O sentido de um fim e dos prêmios Medicis e Femina com o título O papagaio de Flaubert; William Boyd, cuja maioria dos livros foi agraciada com láureas, entre elas os prêmios Whitbread e Somerset Maughan com o livro Um homem bom na África; Kazuo Ishiguro, cujas obras foram traduzidas para mais de 28 países, finalista do prêmio Booker Prize de 2005 com sua obra Não me abandone jamais; lan McEwan, um importante nome da ficção britânica, vencedor do prêmio Somerset Maughan com seu livro inaugural Primeiro amor, últimos ritos e nomeado diversas vezes ao Booker Prize; Vidiadhar Surajprasad Naipaul, autor de obras como Guerrilheiros e Os mímicos, recebeu o Prêmio Nobel de Literatura em 2001; e, finalmente, Salman Rushdie, agraciado com o Booker Prize em 1981 com o título Os filhos da meianoite e com o prêmio Whitbread com $O$ último suspiro do mouro. Ademais, a publicação de seu polêmico livro Versos satânicos Ihe rendeu ainda mais notoriedade.

Nos anos de 1993 e 2003, foram lançadas novas listas de melhores jovens escritores britânicos. Além disso, em 1996 e 2006, saíram as listagens dos meIhores jovens autores norte-americanos. Mais uma vez, muitos nomes tornaram-se aclamados mundialmente pela crítica e pelo público. Dentre eles, Hanif Kureishi, Will Self, Monica Ali, Zadie Smith, cujo primeiro romance, Dentes brancos, recebeu premiações como o Guardian First Book Award, e o Whitbread First Novel Award; Jeffrey Eugenides, vencedor de um Prêmio Pulitzer e autor de As virgens suicidas; Jonathan Safran Froer, ganhador de vários prêmios, entre eles - Guardian First Book Award com Tudo se ilumina; Nicole Krauss, agraciada com prêmios como National Book Award for Fiction 2010 e Book Award Anisfield-lobo 2011; e Jonathan Franzen, vencedor do National Book Award e

\footnotetext{
8 MCCRUM, Robert. The 100 best novels: No 93 - Money: A Suicide Note by Martin Amis
} (1984). The Guardian, 29 jun. 2015. 
do James Tait Black Memorial Prize com As correções.

A partir dessa lista não tão longa em número de nomes, mas extensa em condecorações, é possível notar que, de um modo ou de outro, a opinião da Granta parece mesmo ser capaz de "definir os contornos do cenário literário". Fica evidente, portanto, sua capacidade de interferência ${ }^{9}$ nesse sistema, consolidando literaturas e/ou autores e os conferindo prestígio.

\section{OBSERVANDO A LITERATURA BRASILEIRA CONTEMPORÂNEA}

Ao longo dos anos, a literatura brasileira - assim como sua cultura de uma forma geral - tem ganhado mais atenção estrangeira. Como justificativa para esse olhar externo estar mais atento à literatura emergente desse país, é defendido que "o Brasil vive um momento especial na literatura". ${ }^{10}$ É enfatizado o fato de que nas últimas duas décadas, houve poucos escritores publicados e aclamados no cenário exterior.

Numerosos aspectos estariam colaborando para uma mudança desse cenário de baixa contribuição de escritores brasileiros na literatura global. Entre eles, programas mais consistentes e duradouros de apoio à tradução e ao intercâmbio de agentes do campo literário, um aumento do interesse de editoras e agentes estrangeiros por escritores de língua portuguesa e o Brasil sendo homenageado em diferentes eventos literários ao redor do mundo. ${ }^{11}$ Inclusive, a publicação da revista Granta (em português e em inglês) pode ser uma ferramenta relevante para trazer à tona novos talentos.

Voltando-nos à edição em língua inglesa, publicada em 2012, nos deparamos com uma justificativa um pouco mais extensa, que inclui o Brasil no cenário mundial. A revista é publicada em inglês num período bastante específico. Nesse momento o país cresce economicamente, passando a ser visto como uma promissora fonte de investimentos internacionais. No tocante ao esporte, - Brasil também estava atraindo olhares estrangeiros, pois seria sede da Copa do Mundo de 2014 e também dos Jogos Olímpicos de 2016. O país também chamava atenção musicalmente, já que sua "música está tão vibrante hoje

9 EVEN-ZOHAR, Itamar. Polysystem studies, op. cit.

${ }^{10}$ Granta. Os melhores jovens escritores brasileiros. v. 9. Rio de Janeiro: Objetiva, 2012, p. 9.

${ }^{11}$ O Brasil foi o país homenageado na Feira de Frankfurt em 2013, no Salão do Livro de Paris de 2015, na Feira Internacional do Livro de Gotemburgo (na Suécia) em 2014, na Feira do Livro Infantil e Juvenil de Bolonha em 2014, entre outros. 
quanto quando a bossa nova varreu o mundo nos anos 1950."12 Assim como na edição em português, a edição em inglês também reforça o fato de muito da literatura brasileira ainda ser desconhecida mundo afora. Somado a isso, também há menção a uma mudança na habitual falta de interesse em traduzir o que é escrito no nosso país.

No que diz respeito aos trabalhos de autoria dos escritores da lista, a Granta afirma que os textos se mostram profundamente arraigados às experiências e à cultura de seus autores. ${ }^{13}$ Além disso, "The stories here do not convey an image of an idealized, tropical nation. ${ }^{14}$ Essas últimas afirmações corroboram-se pelo fato de muitos dos contos trazerem localizações não (tipicamente) brasileiras como, por exemplo, o interior da Romênia, viagens a destinos internacionais ou a Alemanha no período do nazismo. Talvez seja por essas temáticas distantes da imagem de país tropical e festivo, que essa geração de jovens escritores seja vista pela revista (edição em inglês) como menos interessada (em comparação com as gerações anteriores) no que tange a uma identidade brasileira. Paralelamente, esses autores também estariam mais desinteressados em explorar questões relacionadas a guerras, revoluções e regimes ditatoriais, ao menos de modo explícito. Para a Granta, possivelmente pelo fato de esse tipo de discurso ter sido mais recorrente na geração anterior a ela, ou seja, com os pais dos jovens escritores. Isso por conta de os pais terem efetivamente vivenciado períodos como a ditadura militar, ao passo que os filhos experimentaram momentos assim apenas a partir das memórias dos mais velhos. Como esses jovens autores (nascidos depois de 1973) não viveram os momentos de luta por liberdade que tomaram conta do Brasil no início dos anos 80 , suas narrativas retratam o posterior desenvolvimento político e econômico vivido pelo país nas décadas subsequentes. De acordo com a revista, esses autores são "Sons and daughters of a nation that is more prosperous and open, they are citizens of the world, as well as Brazilians." ${ }^{15}$

Embora os autores não tenham vivido na pele experiências de ditaduras, momentos de repressão teriam repercutido de forma indireta, porém defini-

\footnotetext{
12 Granta. The best of young Brazilian novelists, v.121, London: Granta, 2012, p. 7. No original: "music is as vibrant today as when bossa nova swept the world in the 1950s".

13 Ibidem, p. 7.

${ }^{14}$ As histórias [...] não transmitem uma imagem de uma nação tropical, idealizada. Ibidem, p. 7.

15 Filhos e filhas de uma nação que é mais próspera e aberta, eles são cidadãos do mundo, assim como brasileiros. Ibidem, p. 7.
} 
tiva, na vida de alguns deles. Familiares de quatro dos vinte selecionados precisaram deixar sua terra natal e emigraram para o Brasil na década de 1970 para escapar de regimes absolutistas. É o caso de Carola Saavedra, Javier Arancibia Contreras, Julián Fuks e Miguel Del Castillo.

O provimento de informações acerca das narrativas e das trajetórias pessoais de alguns autores cumpre um papel bastante específico e intencional: o de recomendar. Tais referências podem ser lidas como "I, $x$, tell you that $y$ has genius and that you must read his book." ${ }^{\prime 16}$ Discursos como esse já apontam para a capacidade de interferência ${ }^{17}$ que veículos midiáticos desse tipo possuem e, consequentemente, para a necessidade de se dar atenção a eles.

\section{AJUDANDO A MOLDAR A LITERATURA BRASILEIRA CONTEMPORÂNEA}

O projeto chamado 'Granta em português' iniciou-se oficialmente em julho de 2011, quando as inscrições foram abertas para escritores de prosa nascidos a partir de 1972 e que tivessem pelo menos um conto de ficção publicado no Brasil. O cumprimento desses requisitos seria indício da construção, em menor ou maior grau, de um caminho no campo literário. ${ }^{18}$ Os candidatos enviaram um trabalho inédito para ser julgado. Em menos de três meses as inscrições haviam alcançado a marca de 247 nomes/trabalhos.

O júri foi composto por "uma equipe de jurados altamente qualificada, editorialmente independente" que contava com "pessoas de diferentes áreas da cena literária". ${ }^{19}$ Formaram o júri Beatriz Bracher, "escritora que atuou por muitos anos na área de edição da Editora $34^{\prime 20}$ e também autora de três romances e de uma coletânea de histórias; Cristovão Tezza, ex-professor universitário, autor de obras como $O$ filho eterno, vencedor dos mais importantes prêmios literários brasileiros e finalista do International IMPAC Dublin Literary Award em 2012; Samuel Titan, editor e tradutor de Flaubert, Canetti e Capote, entre outros autores clássicos e contemporâneos, e professor de literatura comparada da USP; Manuel da Costa Pinto, jornalista, crítico e colunista do jornal Folha de São Paulo; Italo Moriconi, editor, professor de literatura comparada e brasileira

\footnotetext{
16 Eu, $x$, te digo que $y$ possui genialidade e que você deve ler seu livro. GENETTE, Gerárd. Paratexts: thresholds of interpretation, op. cit., p. 267.

17 EVEN-ZOHAR, Itamar. Polysystem studies, op. cit.

18 Granta. Os melhores jovens escritores brasileiros, op. cit., p. 8.

19 Ibidem, p. 8.

20 lbidem, p. 8.
} 
na UERJ, crítico literário e poeta; Benjamin Moser (nome sugerido pela Granta inglesa), norte-americano, biógrafo de Clarice Lispector, tradutor e escritor; e Marcelo Ferroni, editor da Alfaguara, escritor e um dos coordenadores na Granta em português. A Granta defende que a presença de um jurado estrangeiro "enriqueceu o processo de escolha dos autores", com sua "visão 'externa". ${ }^{21}$

Para a elaboração dos melhores jovens escritores brasileiros, foram selecionados vinte autores, todos nascidos a partir de 1972, que, com sua escrita, "contribuem para mudar o panorama das letras no país".22 Após um ano de trabalho de triagem, o volume é entregue aos leitores. Reino Unido e Estados Unidos também receberam sua versão em língua inglesa e Espanha e países da América Latina receberam sua versão em língua espanhola. Recentemente, a revista tem ultrapassado mais e mais fronteiras, aterrissando em países como Itália, Noruega, Bulgária, China e Suécia, podendo a edição brasileira ganhar versões nesses países. ${ }^{23}$

Os textos elencados retratam uma parcela significativa dos escritores em atividade no país. Todos têm idade inferior a 40 anos e possuem ao menos um conto publicado. Alguns, inclusive, receberam premiações por seus trabalhos. É o caso de Michel Laub, que, em 2011, ganhou o Prêmio Bravo! de Literatura; Tatiana Salem Levy, que foi agraciada com o Prêmio São Paulo de Literatura por seu romance inaugural que foi posteriormente traduzido para seis países; Luisa Geisler, nascida em 1991, que venceu o Prêmio SESC de Literatura; e Daniel Galera que já recebeu o prêmio de melhor romance da Fundação Biblioteca Nacional. No rol de Granta em português há vários autores ainda pouco conhecidos, mas que foram selecionados por mostrarem um "trabalho consistente". ${ }^{24}$ É o caso de Miguel Del Castillo, Vinícius Jatobá e Cristhiano Aguiar.

A totalidade dos contos brasileiros foi escolhida pelo júri que acredita que "os textos compõem um mosaico surpreendente de estilos e temas e chama a atenção pelo vigor e apuro estilístico - o acerto nos detalhes, a busca por uma linguagem coesa, o desenvolvimento cuidadoso de personagens." 25 As obras retratam, majoritariamente, uma realidade urbana, explorando as complexas relações humanas familiares e amorosas, através de temáticas distintas, como

\footnotetext{
21 lbidem, p. 9.

22 Ibidem, p. 5.

23 Ibidem, p. 5.

24 Ibidem, p. 6.

25 Ibidem, p. 6.
} 
a perda de um ente querido, a busca por identidade, autoconhecimento ou algo menos abstrato (como obras de um artista falecido), confrontos culturais e assassinato. Embora nem todos os vinte escritores tenham nascido no Brasil, eles se enquadraram como autores brasileiros por serem filhos de pai ou mãe brasileiro, terem vindo morar muito cedo no Brasil e/ou por terem se radicado nesse país e construído uma carreira literária aqui.

Grande parte das informações sobre as edições 9 e 121 aqui presentes são oriundas da introdução, que constitui um importante paratexto com a função de assegurar recepção e leitura mais adequadas, segundo a visão do autor, nesse caso a Granta. Por sua localização ser inicial, a introdução também cumpre o papel de monitorar a leitura, no sentido de determinar o porquê e como o livro deve apreciado. ${ }^{26} \mathrm{O}$ discurso proferido pela Granta atribui alto valor tanto aos textos (vinte contos) quanto a seus autores, destacando características ditas positivas das narrativas e dos escritores, insistindo "on the originality, or at least the novelty, of the subject [...] on the traditional nature of its subject (an obvious guarantee of quality)."27

Uma das razões para a presença das informações acima seria deixar o leitor ciente da origem do trabalho, algo extremamente pertinente em se tratando de uma obra divulgando "os melhores jovens escritores brasileiros". O leitor é informado sobre as circunstâncias nas quais a obra foi elaborada, as etapas de criação e as fontes. ${ }^{28}$ Tudo isso para tentar garantir uma interpretação mais adequada às políticas editoriais da revista Granta.

\section{AUTOR(IZANDO): CONSTRUINDO E DESCONTRUINDO CÂNONES}

Certamente, as listagens com os "melhores escritores" agregam mais notoriedade aos nomes, já que, a partir do momento em que ganham esse destaque na mídia impressa, passam também a ganhar mais popularidade junto ao público que, provavelmente, deve buscar mais informações acerca dos escritores e de seus trabalhos. Cria-se, assim, uma dinâmica do tipo: se [as autoridades dessa revista] estão falando dessa pessoa, é porque ela deve ser 'boa', por isso, vou ler suas obras. Dessa forma, discursos como os criados e veiculados por

\footnotetext{
${ }^{26}$ GENETTE, Gerárd. Paratexts: thresholds of interpretation, op. cit., p. 197.

${ }^{27} \mathrm{Na}$ originalidade, ou ao menos da novidade, de seu assunto [...], na natureza tradicional de seu assunto (uma óbvia garantia de qualidade). Ibidem, p. 200.

28 Ibidem, p. 210-211.
} 
instituições desse tipo atuam na promoção de vendas e compras de produtos literários e no estabelecimento de tipos de consumo, movimentando as engrenagens do polissistema. Afinal, "proliferating the market lies in the very interest of the literary system." ${ }^{29}$

A Granta, nas suas condições de revista literária e editora, pode ser concebida como instituição, no sentido que Even-Zohar dá ao termo, já que dispõe de autoridade e legitimidade para sancionar e/ou rejeitar normas. Já no tocante aos paratextos de Genette, para quem cada um dos elementos constituidores de uma obra possui uma função literária, o simples fato de existir uma afiliação acadêmica (ou a qualquer entidade célebre) ou a premiações literárias consiste em importante característica paratextual que merece atenção do leitor sob pena de ser facilmente manipulado.

A Granta afirma não ter uma agenda política ou literária, mas "it does has a belief in the power and urgency of the story and its supreme ability to describe, illuminate and make real." ${ }^{\prime 30}$ Considerando ambas as afirmações, é importante lembrarmos o dialogismo de Bakhtin, que nos explica que o discurso absolutamente neutro é impraticável. ${ }^{31}$ Por trás das palavras, aparentemente neutras, parecem residir valores bastante particulares que retratam uma maneira específica de enxergar sua própria cultura (no caso a de língua inglesa).

Publicações como a Granta desempenham papel de disseminadores e, consequentemente, de formadores de opinião. É possível explorar essas questões sob algumas óticas. Uma delas seria discutir, em um contexto foucaultiano, a função de autor exercida pelas revistas, num sentido de deter autoridade para fazer circular esse discurso que aponta 'os melhores' autores e 'boa' e 'promissora' literatura. A outra ótica seria refletir, dentro da teoria de Bourdieu, sobre como as revistas materializam uma 'linguagem autorizada' que confere legitimidade a seus discursos.

Inicialmente, é fundamental sublinhar que a categoria 'autor' que se pretende investigar neste momento não estaria representada por um único indivíduo responsável pela criação de alguma obra, seja ela um texto literário, uma pintura ou uma música. O 'autor' aqui em foco seria a revista Granta (em suas

\footnotetext{
29 Proliferar o mercado reside no interesse primordial do sistema literário. EVEN-ZOHAR, Itamar. Polysystem studies, op. cit., p. 39.

30 Tem uma crença no poder e na urgência da história e na sua habilidade suprema de descrever, iluminar e tornar real. Granta: the magazine of new writing.

${ }^{31}$ BAKHTIN, Mikhail. Estética da criação verbal. Trad. Maria Ermantina Galvão G. Pereira. 2. ed. São Paulo: Martins Fontes, 1997.
} 
duas edições aqui em foco), responsável pela criação da obra "Os melhores jovens escritores brasileiros", cuja responsabilidade autoral não recai sobre um único indivíduo, mas sim sobre um grupo de pessoas envolvidas desde o lançamento do projeto 'Granta em português', passando pela formação do júri, pela triagem dos autores e suas obras, até a publicação do título.

A ideia é partir das concepções de autor apresentadas por Foucault e aplicar algumas delas à revista (enquanto revista e editora), ou seja, tomá-la como autor, já que, dentre outras características, não consta um nome de autor na capa. É possível, portanto, que o grupo da Granta em português, formado por diretor, editor, assistente editorial, gerente de produção, coordenador de revisão, revisão, capa e editoração eletrônica, constitua a entidade 'autor' e, por isso, responsável pela circulação do material contido na revista. Mas é preciso lembrar que esse grupo não inclui os jurados que selecionaram os textos publicados, cujo trabalho foi imprescindível para a elaboração da revista. Segundo consta, todos os direitos desta edição são reservados à Editora Objetiva Ltda. No caso da revista Granta (inglesa), o grupo 'autor' seria composto por uma diretora-geral, um editor, uma subeditora, um editor assistente e um assistente editorial. Quanto aos direitos, são reservados à Granta Publications. De igual forma, o grupo não abarca o júri que julgou e escolheu os contos publicados.

Em sua obra $O$ que é um autor?, Foucault ${ }^{32}$ revisita e levanta importantes questionamentos para discutir sobre a categoria chamada 'autor': "que importa quem fala?", "o que é uma obra?" e "o que é um nome de autor? E como funciona?". Sobre esta última indagação, Foucault conclui que o nome próprio do autor vai muito além das funções indicadoras e não se qualifica como um nome próprio como os outros (de não autores). ${ }^{33} \mathrm{Assim}$, o nome Granta não funciona como um nome qualquer. Trata-se de um nome que desempenha uma força maior do que a simples descrição de uma revista. Este nome "exerce relativamente aos discursos um certo papel: assegurar uma função classificativa". O nome Granta, que existe desde 1889, "permite reagrupar um certo número de textos, delimitá-los, selecioná-los, opô-los a outros textos." ${ }^{34}$ Assim como o nome Machado de Assis nos possibilita reunir vários textos de sua autoria, o

\footnotetext{
32 FOUCAULT, Michel. O que é um autor? Trad. Antônio Fernando Cascais e Eduardo Cordeiro. Belo Horizonte: FALE/UFMG, 2011. p. 51-82.

33 Ibidem, p. 53-58.

34 Ibidem, p. 59.
} 
nome Granta usufrui de autoridade para compilar uma série de textos, enquadrá-los em determinados tipos, contrapô-los e julgá-los. A revista, por meio de suas compilações "manifesta a instauração de um certo conjunto de discursos [...] no interior de uma sociedade e de uma cultura."35 Por meio de uma legitimação que lhe fora e é investida, a revista faz circular sua opinião, que pode ser tomada como verdade por seus leitores que a atestam como entidade autorizada. O mesmo ocorre quando lemos informações impressas em jornais ou ouvimos notícias no rádio. Por isso, segundo as palavras de Foucault, é possível dizer que "numa civilização como a nossa, uma certa quantidade de discursos são providos da função 'autor'." ${ }^{36}$ É por isso que o ponto de vista aqui exposto defende que a revista Granta é provida da função 'autor', já que ela é “característica do modo de existência, de circulação e de funcionamento de alguns discursos no interior de uma sociedade." ${ }^{37}$ Essa ideia pode ser estendida a todas as listas do tipo "os melhores" (100 livros da história, 100 filmes para assistir antes de morrer, autores da história, etc.). Livros assim podem exercer forte impacto na literatura, no que se refere à produção, reprodução, disseminação, popularidade, rentabilidade e autoridade.

Talvez se queira trazer à tona o fato de muitos dos autores que compuseram antigas listagens da Granta (e que compõem os atuais) serem premiados para justificar a confiabilidade desse tipo de lista prescritiva. No entanto, não podemos ser ingênuos e ignorar o fato de que os prêmios literários são apenas outra maneira de prescrever o que é 'o melhor', mesmo que seja de modo menos implícito do que fazer listas. As premiações também são um meio de promover e exaltar um número específico de livros ou autores, com base em critérios e valores particulares. E é por razões desse tipo que a Granta poderia ser classificada como "fundador[a] de discursividade"38, já que ela não é apenas responsável pela criação das edições, dos livros e das informações veiculadas; ela viabiliza a criação de cânones e de nomes consagrados; ela contribui "com modos de circulação, de valorização, de atribuição e de apropriação dos discursos". 39

Conforme reforçado por Foucault, "a função autor desempenha hoje um

\footnotetext{
35 Ibidem, p. 59.

36 Ibidem, p. 59.

37 Ibidem, p. 50.

38 Ibidem, p. 65.

39 Ibidem, p. 71.
} 
papel preponderante nas obras literárias" 40 , haja vista que o autor goza de "capacidade de alterar, de reorientar o campo epistemológico ou o tecido discursivo." ${ }^{11}$ Assim, a revista Granta, dotada de sua autoridade, seria capaz de reorientar os modos como determinados textos/autores são vistos pela sociedade e, desse modo, interferir no discurso literário, conferindo mais ou menos valor a certos escritores e/ou obras. A esse respeito, Agamben ${ }^{42}$ acrescenta as diferentes características da função autor no nosso tempo: "um regime particular de apropriação [...]; a possibilidade de autenticar os textos, constituindo-os em cânone ou, pelo contrário [...]; a possibilidade de construir uma função transdiscursiva, que constitui o autor, para além dos limites da sua obra". A revista Granta parece ser dotada de tais características, pois tem autoridade para autenticar textos, para auxiliar na canonização ou não de autores e obras e para influenciar outros discursos.

O discurso prescritivo da revista Granta se concretiza por meio de uma linguagem autorizada. Conforme explicado por Bourdieu, a língua é muito mais do que uma ferramenta que utilizamos para nos comunicarmos e alcançarmos conhecimento. Ela é "um instrumento de poder"43. Com ela "não procuramos somente ser compreendidos, mas também obedecidos, acreditados, respeitados, reconhecidos." ${ }^{\text {44 }}$ A Granta, detentora de autoridade, dispõe do direito de anunciar sua opinião e tê-la respeitada. Dito de outra maneira, a revista detém "linguagem legítima como linguagem autorizada, como linguagem de autoridade". ${ }^{45}$ Indo mais adiante, sua "competência implica o poder de impor a recepção. ${ }^{\prime 46}$ Com sua opinião respeitada e validada, o público adere ao discurso proferido e, com isso, o confirma ainda mais através do consumo dos produtos anunciados por ela; neste caso, obras 'boas' ou 'bons' autores, que valem a pena ser lidos.

\section{CONSIDERAÇÕES FINAIS}

É complicado determinar o que ocorre primeiro: se o discurso da Granta é reflexo da opinião da crítica, dos jornalistas e dos estudiosos de literatura ou se

\footnotetext{
40 Ibidem, p. 61.

${ }^{41}$ Ibidem, p. 80.

42 AGAMBEN, Giorgio. O autor como gesto. In: Profanações. Trad. Selvino J. Assmann. São Paulo: Boitempo, 2007, p. 50.

${ }^{43}$ BOURDIEU, Pierre. A economia das trocas linguísticas, op. cit., p. 6.

${ }^{44}$ Ibidem, p. 6.

45 Ibidem, p. 6.

46 Ibidem, p. 6.
} 
a opinião destes é influenciada pelo discurso daquela. A questão é que os dizeres parecem caminhar juntos, um reiterando os discursos dos outros. Estas autoridades culturais parecem acreditar no mérito e no benefício de prescrever 'os melhores autores' ou 'os melhores livros' aos leitores, seja por meio de listas ou prêmios. E ninguém parece contestar essa autoridade cultural ou a legitimidade dos discursos.

Esta ação de descrever 'os melhores autores' não consiste em uma mera seleção e validação de certos autores por meio de listas ou condecorações. De modo mais complexo, parece ser a constituição e a disseminação de uma estratégia que determina quem são os 'melhores autores' em distintos momentos. Esta estratégia se concretiza numa série de critérios linguísticos: exatidão, classificações literárias (como literatura e ficção), conceitos artísticos (como arte literária), valores estéticos e estrutura narrativa. Certos critérios ficam evidentes quando a revista apresenta o conjunto dos textos que a compõe como "um mosaico surpreendente de estilos e temas" que "chama a atenção pelo vigor e apuro estilístico - o acerto nos detalhes, a busca por uma linguagem coesa, o desenvolvimento cuidadoso de personagens." ${ }^{47}$

A revista ou a editora, já que publicou outros títulos parecidos ("Os melhores jovens escritores britânicos", "Os melhores jovens escritores norte-americanos", "Os melhores jovens escritores em espanhol"), goza de status de autoridade cultural e de legitimidade, na qual diversos indivíduos e grupos (elites, escritores profissionais em ascensão, nacionalistas, intelectuais, críticos, educadores e editoras) buscam instaurar seus gostos, interesses, preferências e crenças. É por meio de posicionamentos dessa ordem que se configuram, dentro do campo literário, noções de valores que balizam o que deve ou não ser lido, o que precisa ou não ser preservado. Esse discurso do que é 'bom' ou do que é o 'melhor' é um desdobramento de questões literárias como marginalização, exclusão, canonização. Dentro dessa dinâmica dos discursos, há regras que "determinam quem pode falar (de fato e de direito), a quem e como" . ${ }^{48}$ Como reitera Bourdieu, a palavra não é tomada por qualquer um. A revista Granta não se qualifica como qualquer um. É um veículo de informações de longa data (1889), fundada por uma instituição de alto prestígio e imaculada reputação e bem consolidada (Universidade de Cambridge). Sua palavra, portanto, "merece

47 Granta. Os melhores jovens escritores brasileiros, op. cit., p. 6.

${ }^{48}$ BOURDIEU, Pierre. A economia das trocas linguísticas, op. cit., p. 6. 
ser acreditada, obedecida" ${ }^{\prime 4}$, pois tem credibilidade.

Os dados aqui apresentados e discutidos sugerem que a literatura e, consequentemente, os textos que se ocupam da literatura são aspectos integrantes, frequentemente centrais e com muito poder, em uma sociedade. Essas obras são elementos chave para a compreensão de qualquer sistema cultural, sendo útil não apenas como uma hermenêutica do texto, mas, sobretudo, como uma forma de falar sobre o mundo. ${ }^{50}$ Compreende-se que as dinâmicas literárias produzem numerosos efeitos e nos oferecem diversas respostas. Todo e qualquer arranjo social constitui um sistema de significados. Devemos estar sempre atentos às formas pelas quais as sociedades representam o dito "melhor", servem-se dele para articular regras de relações sociais, neste caso, algumas das que se dão no polissistema literário. Esse tipo de discurso nada mais é do que uma ramificação de questões literárias como marginalização, exclusão ou canonização.

As reflexões aqui expostas não têm o intuito de contestar a credibilidade e a autoridade da revista Granta, mas apenas de analisar a sua inserção dentro do sistema literário. A edição contendo a lista com "Os melhores jovens escritores brasileiros" apresentou-se como um ponto de partida para discutir sobre sua 'função autor', desempenhada através de sua linguagem autorizada que the confere legitimidade para criar e difundir discursos. Nesse sentido, este trabaIho teve por objetivo, através de análise da revista Granta, reiterar a importância de discursos criados e difundidos por veículos desse tipo, com o intuito de desvendar possíveis interesses, desdobramentos e demais relações existentes em práticas literárias dessa ordem.

49 Ibidem, p. 7.

50 PYM, Anthony. Exploring translation theories. London / New York: Routledge, 2010, p. 148. 